\title{
Adaptation and cross-cultural validation of the Brazilian version of the Warwick-Edinburgh mental well-being scale
}

\author{
Jefferson Jovelino Amaral dos Santos ${ }^{1 *}$, Telma Aparecida da Costa ${ }^{2}$, Juliane Honório Guilherme ${ }^{3}$, Watusi Camila da Silva ${ }^{3}$, \\ Lilian Regina Lengler Abentroth ${ }^{3}$, Jessica Aline Krebs ${ }^{4}$, Priscila Sotoriva ${ }^{4}$

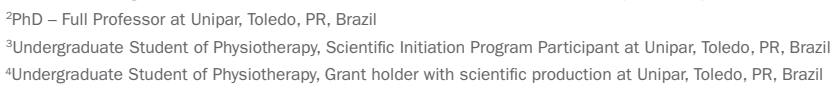

\section{SUMMARY}

Objective: the Warwick-Edinburgh mental well-being scale (WEMWBS) was designed to assess the level of mental well-being of a population or specific groups. The scale consists of 14 items covering functional psychological aspects, as well as well-being. The final score is calculated by adding up the response of each item, ranging from 1 to 5 , obtaining a result from 14 to 70 points.

Methods: the procedure was developed in accordance with the protocol recommended by the World Health Organization covering translation, back translation, semantic equivalence, expert evaluation of the previous steps, pre-test and final version of the instrument. Following, the final version was applied to a sample of 122 individuals and the data were subjected to descriptive statistical analysis, factor analysis, internal consistency and correlation with other validated instruments.

Results: we performed the instrument's adaptation to the Portuguese spoken in Brazil, replacing terms to approximate the language to expressions of everyday life. The final version showed similar results to those from the original version, demonstrated by factor analysis, internal consistency (Cronbach's alpha: 0.89 ) and positive correlation with instruments validated to the Portuguese language.

Conclusion: the Brazilian version of the WEMWBS proved to be easy to use and understand, showed high internal consistency and construct validity similar to the original instrument.

Keywords: mental health, validation studies, quality of life, questionnaires, scales.

\section{INTRODUCTION}

Mental health is characterized as a state of well-being in which the individual realizes his or her own abilities, can cope with the normal stresses of life, can work productively, and is able to make a contribution to his or her community. Its promotion involves multisectoral action, including governmental (health, education, environment, transport) and non-governmental initiatives (churches, clubs and others). ${ }^{1}$

Current research shows that well-being is directly related to better overall health levels, disorders and physical disabilities, and even less use of health services. ${ }^{2,3}$

In order to address the need to evaluate the mental well-being of the general population, the Warwick-Edinburgh mental well-being scale (WEMWBS) was created.
The original version of the instrument showed strong psychometric consistency (test-retest reliability at 0.83 , and internal consistency at 0.91), being fast and easy to apply, as well as a useful tool to monitor the general well-being of a population. ${ }^{4,5}$ The WEMWBS, for its applicability, has been used and adapted to several languages, for different cultures and populations. ${ }^{6-10}$

It measures the positive aspects of mental health over a period of two weeks prior to its application. It is an ordinal scale that uses 14 phrases covering hedonic (happiness, joy, contentment) and eudaimonic (psychological functioning, autonomy, positive relationship with others, sense of purpose in life) aspects. Each item is answered based on a 5-point Likert-like scale, from 1 (Never) to 5 (Always). The values obtained in each answer are added 
yielding a total score, ranging from a minimum 14 to a maximum 70 points, and the higher the final score, the better the state of mental well-being.

This study aimed to adapt and validate the WEMWBS scale to the Portuguese spoken in Brazil.

\section{Methods}

First, we requested authorization to the authors of the WEMWBS scale for use and cross-cultural adaptation into Portuguese spoken in Brazil. We opted for the basic structure of the translation and back-translation protocol recommended by the World Health Organization (WHO), which aims to enable the translation into languages other than English, so that the translated versions maintain a conceptual equivalence in each of the countries and cultures. The instrument should be natural, acceptable and applicable in practically the same way as in the original language. ${ }^{11}$

In step 1, two health professionals and a native-speaking English teacher, who was also fluent in Portuguese, conducted, independently, three different translations of the original instrument from English into Brazilian Portuguese. Translators were blinded to each other. These professionals were chosen because they were familiar with the constructs used in the instrument. We requested that they emphasized the semantic consistency of the terms and constructions.

Step 2 involved three Brazilian health professionals, all bilingual, who performed back-translations of the preliminary translated versions back into English, independently and without knowledge of the original scale.

In step 3, evaluation of semantic equivalence was performed by the authors of this study, and the preliminary Brazilian Portuguese version was improved based on the translations and back-translations. To compose the Brazilian version of the questionnaire, items were incorporated from one of the three versions, which may have been slightly modified in order to find the best combination of criteria for semantic equivalence. The consensus back-translation was sent to the authors of the original instrument, who agreed with it.

In step 4 , this version was presented to 10 individuals ( 6 women and 4 men) aged 20 to 40 years, two of them with primary education, 5 with high school education and 3 , university/college education. In all cases, the respondents were asked about the understanding of the questions and whether the alternatives were clear. All participants demonstrated and said that they understood all the questions and that they were simple, objective and easy to understand. Based on these considerations, the final Brazilian version of the WEMWBS was prepared.
Lastly, the final Brazilian version was used with 122 college students at Universidade Paranaense. All participants signed an informed consent after receiving information about the study procedures, confidentiality criteria and voluntary nature of their participation.

To calculate the sample size, we considered other studies that demonstrated the one-dimensionality of the WEMWBS scale ${ }^{4,12}$ and, therefore, samples of approximately 100 individuals were sufficient to carry out an exploratory factor analysis. ${ }^{13}$

Sample characteristics were presented using descriptive statistics for mean and standard deviation (Table 1). Dimensionality was assessed using exploratory factor analysis, using principal components analysis with varimax rotation. The number of factors was determined by examining the slope in the sedimentation graph. Reliability was assessed using Cronbach's alpha and due to the absence of a "gold standard", we used two instruments to assess construct validity, using Spearman's correlation coefficient: the WHO-Five Well-being Index (WHO-5) ${ }^{14}$ and the Well-Being Manifestation Measure Scale (WBMMS). ${ }^{15}$ The first is a short assessment tool, written in a positive way to assess the level of emotional well-being over a period of 14 days. The second scale assesses psychological well-being, using six subscales plus a global index of well-being that includes items such as: feeling confident, appreciated, loved and satisfied with one's own achievements; having balance between family, personal and professional activities; social involvement in general activities; sociability toward others; control of self and events; ability to face life's difficulties calmly and constructively; and happiness, which is related to feeling good, fit and having a good attitude. Both instruments have been validated in Portuguese. ${ }^{16,17}$

\section{TABLE 1 Demographic characteristics of the sample.}

\begin{tabular}{lll} 
Gender & N & $\%$ \\
\hline Female & 99 & 81.1 \\
\hline Male & 23 & 18.9 \\
\hline Race & & \\
\hline Yellow & 1 & 0.8 \\
\hline White & 102 & 83.6 \\
\hline Black & 3 & 2.5 \\
\hline Mixed & 16 & 13.1 \\
\hline
\end{tabular}

Perceived health status

\begin{tabular}{lcc}
\hline Very good & 42 & 34.4 \\
\hline Good & 65 & 53.3 \\
\hline Regular & 13 & 10.7 \\
\hline & & (Continue)
\end{tabular}


TABLE 1 (Cont.) Demographic characteristics of the sample.

\begin{tabular}{lll} 
Perceived health status & N & $\%$ \\
\hline Bad & 2 & 1.6 \\
\hline Very bad & 0 & 0.0
\end{tabular}

Housing type

\begin{tabular}{lll}
\hline Owner-occupied & 83 & 68.0 \\
\hline Mortgaged & 6 & 4.9 \\
\hline Renter-occupied & 31 & 25.4 \\
\hline Other & 2 & 1.6 \\
\hline
\end{tabular}

\section{Income}

\begin{tabular}{lll}
\hline Up to 1 minimum wage & 3 & 2.46 \\
\hline$>1$ to 2 minimum wages & 15 & 12.30 \\
\hline$>2$ to 3 minimum wages & 38 & 31.15 \\
\hline$>3$ to 5 minimum wages & 39 & 31.97 \\
\hline$>5$ to 10 minimum wages & 18 & 14.75 \\
\hline$>10$ to 20 minimum wages & 9 & 7.38 \\
\hline
\end{tabular}

Main income provider in the household

\begin{tabular}{lll}
\hline Respondent & 10 & 8.20 \\
\hline Spouse & 17 & 13.93 \\
\hline Father/Mother & 91 & 74.59 \\
\hline Other Person & 4 & 3.28 \\
\hline
\end{tabular}

Marital status

\begin{tabular}{lll}
\hline Single & 99 & 81.15 \\
\hline Married & 16 & 13.11 \\
\hline Common-law partner & 6 & 4.92 \\
\hline Divorced & 1 & 0.82 \\
\hline
\end{tabular}

Minor children under guardianship

\begin{tabular}{lll}
\hline Yes & 10 & 8.2 \\
\hline No & 112 & 91.8 \\
\hline
\end{tabular}

\section{Professional status}

\begin{tabular}{lll}
\hline Studies only & 46 & 37.7 \\
\hline Works and studies & 76 & 62.3 \\
\hline
\end{tabular}

\section{Results}

The Brazilian version of the WEMWBS was applied to 122 individuals of both genders (99 women and 23 men) with a mean age of $21.5 \pm 4$ years, who voluntarily agreed to participate in the study. They all signed an informed consent form and had their identities concealed. The general sample yielded a score of $51.8 \pm 8$ points. Specifically, male participants had statistically higher scores compared to the women, $54.56 \pm 7$ and $51.18 \pm 7$, respectively ( $p>0.05$ ).

Each individual component presented the mean values shown in Table 2.

Using factor analysis with all the variables, the KaiserMeyer-Olkin (KMO) measure was 0.875 indicating that this analysis is perfectly suitable for processing these data. The result of the Bartlett's test of sphericity, based on the statistical distribution of chi-square, was 692,613 with significance level of 0.001 , allowing us to reject the null hypothesis of no data correlation. Analyzing the commonalities, we found that questions number four, six, eight, nine, ten, eleven and fourteen scored higher than 0.50 using the extraction method and, based on that, factor analysis was repeated using only these variables (components).

First, we determined the self-values that represent the variability of each component and the percentage of variance explained through each of these values, as shown in Table 3.

In order to decide the number of factors selected to represent the latent structure of the data, we first considered using a latent root criterion, which selects only factors with self-values greater than 1 . Given that, two factors were selected, corresponding to $65.695 \%$ of the total variance. This result is also satisfactory for the variance percentage criterion, which suggests that a minimum explanation of variability of $60 \%$ is sufficient.

Table 4 shows the factor loadings representing the contribution of each variable to compose the components. Following that, we used Varimax rotation with Kaiser Normalization factor to make it easier to see the representative factor loadings on each factor.

Based on the criterion that suggests that factor loadings above " 0.50 " are considered of practical significance, we were able to point out the significant variables in each component. Variables with the highest coefficients are more correlated with the factor. ${ }^{18}$

The reliability of the scale was checked through internal consistency, analyzed using Cronbach's alpha test. All correlations between items were positive and significantly different from zero, which indicates that it is possible to compose a scale with these items, since they measure a single attribute. In this study, Cronbach's alpha was 0.89 .

Construct validity was assessed using Spearman correlation coefficient between WEMWBS and the WHOFive Well-being Index (WHO-5), and the well-being manifestation measure scale (WBMMS) (Table 5). In both situations, there was a statistically significant correlation between the instruments $(\mathrm{p}<0.001)$.

\section{Discussion}

The interest in well-being and mental health, as well as their potential to improve both quality of life and disease prevention, has grown substantially lately. ${ }^{6}$ Their personal, social and economic impact extrapolates the clinical field itself. For example, in Europe, the cost of mental health disorders and well-being has been estimated in approximately 789 billion Euros per year ${ }^{19}$ and, today, this is the biggest economic challenge to health in the continent. ${ }^{20}$ 
TABLE 2 Mean values obtained from each component of the Brazilian version of the WEMWBS.

\begin{tabular}{|c|c|c|c|c|c|c|}
\hline No. & Question (approved final version) & Mean & Standard deviation & Minimum & Maximum & $\mathbf{N}$ \\
\hline 1 & I've been feeling optimistic about the future. & 3.99 & 0.904 & 1 & 5 & 122 \\
\hline 2 & I've been feeling useful. & 3.75 & 0.921 & 1 & 5 & 122 \\
\hline 3 & I've been feeling relaxed. & 3.33 & 0.886 & 1 & 5 & 122 \\
\hline 4 & I've been feeling interested in other people. & 3.44 & 0.900 & 1 & 5 & 122 \\
\hline 5 & I've had energy to spare. & 3.07 & 0.942 & 1 & 5 & 122 \\
\hline 6 & I've been dealing with problems well. & 3.40 & 0.789 & 1 & 5 & 122 \\
\hline 7 & I've been thinking clearly. & 3.67 & 0.765 & 2 & 5 & 122 \\
\hline 8 & I've been feeling good about myself. & 3.70 & 0.897 & 1 & 5 & 122 \\
\hline 9 & I've been feeling close to other people. & 3.77 & 0.841 & 2 & 5 & 122 \\
\hline 10 & I've been feeling confident. & 3.75 & 0.947 & 1 & 5 & 122 \\
\hline 11 & I've been able to make up my own mind about things. & 3.99 & 0.777 & 2 & 5 & 122 \\
\hline 12 & I've been feeling loved. & 3.95 & 0.832 & 2 & 5 & 122 \\
\hline 13 & I've been interested in new things. & 4.04 & 0.807 & 2 & 5 & 122 \\
\hline 14 & I've been feeling cheerful. & 3.95 & 0.822 & 2 & 5 & 122 \\
\hline
\end{tabular}

\section{TABLE 3 Total explained variance.}

\begin{tabular}{lllll} 
Component & Self-value & \% of explained variance & Cumulated self-value & \% of cumulated explained variance \\
\hline 1 & 3.571 & 51.009 & 3.571 & 51.009 \\
\hline 2 & 1.028 & 14.686 & 4.599 & 65.695 \\
\hline 3 & 0.683 & 9.756 & 5.282 & 75.451 \\
\hline 5 & 0.573 & 8.184 & 5.855 & 83.635 \\
\hline 6 & 0.453 & 6.472 & 6.308 & 90.107 \\
\hline 7 & 0.375 & 5.357 & 6.683 & 95.464 \\
\hline
\end{tabular}

Extraction method: principal component analysis.

TABLE 4 Factor loadings in the composition of components.

\begin{tabular}{lll}
\hline \multicolumn{3}{l}{ Component } \\
\hline 4 & $\mathbf{1}$ & $\mathbf{2}$ \\
\hline 6 & 0.047 & 0.961 \\
\hline 8 & 0.729 & -0.167 \\
\hline 9 & 0.803 & 0.097 \\
\hline 10 & 0.737 & 0.275 \\
\hline 11 & 0.842 & 0.053 \\
\hline 14 & 0.721 & -0.039 \\
\hline
\end{tabular}

TABLE 5 Correlations between WEMWBS and other well-being scales (construct validity).

\begin{tabular}{lllll} 
& $\mathbf{N}$ & Spearman & $\mathbf{t}(\mathbf{N}-2)$ & $\mathbf{P}$ \\
\hline WEMWBS $\times$ WHO-5 & 122 & 0.594653 & 8.10229 & $<0.001$ \\
\hline WEMWBS $\times$ WBMMS & 122 & 0.696951 & 10.64638 & $<0.001$ \\
\hline
\end{tabular}


In Brazil, due to its huge territorial dimension, there are no reliable estimates regarding impact of disorders of well-being and mental health, and its total cost. The country invested about $2.5 \%$ of the federal health budget in the Mental Health Policy in recent years. In the Americas, $33.3 \%$ of the countries that have this data allocate over $5 \%$ of their health budgets to mental health. Still, considering the American countries, $44.4 \%$, including Brazil, spend 2 to $5 \%$ of their health budgets in mental health only, which is a major problem to be addressed in coming years in terms of mental health policy. ${ }^{21}$

Mental well-being is still not studied enough, in part due to the absence of reliable instruments for such demand. Therefore, the WEMWBS scale is an instrument that will meet the needs of individual and population assessments. ${ }^{5,7,9,22}$

Valid and reliable instruments for research are extremely important in comparisons between different contexts and samples. They are recommended when the goal is to assess the validity of an instrument, which is achieved through continuing research on the subject. ${ }^{23}$

In the present study we developed the Brazilian Portuguese version of the WEMWBS according to the parameters recommended by the World Health Organization $^{11}$ and other current studies. ${ }^{24}$ The Brazilian WEMWBS proved to be a comprehensive tool that can provide safe and consistent results regarding overall well-being, life satisfaction and perceived health status - important components of mental well-being. Data from this study indicate that the WEMWBS can be a useful tool in the assessment of mental well-being at all levels of care. The time required for application was short, allowing it to be incorporated into routine clinical history.

The mean score of the sample was $51.8 \pm 8$ points. Similar results were found in the original studies of instrument validation, in which the sample of students reached 50 points on average and the general population, 51 points. ${ }^{4}$ Other studies have shown scores of 53.5 points in a Spanish sample, ${ }^{6} 52.34$ points in a sample of Chinese origin, and 52 points in a third sample of Pakistani origin.?

The adequacy of the factor analysis was confirmed by $\mathrm{KMO}$ and Bartlett's test of sphericity, which in turn made it possible to verify the adequacy of the data for application of factor analysis. In this study, the factor analysis was suitable for processing the data, with two factors accounting for approximately $65.7 \%$ of the variance found. No other factor showed self-value greater than 1. KMO, which assesses the level of inter-correlation among the variables, was 0.875 , suggesting suitability of data for fac- tor analysis. The values used in this test range from 0 to 1 ; the closer to 1 , the more appropriate the sample for factor analysis. ${ }^{25}$

The internal consistency among the fourteen questions was tested using Cronbach's alpha, which resulted in 0.89 , indicating high reliability of the answers given to the questions. Cronbach's alpha is one of the psychometric indicators most commonly used to determine the reliability and internal validity of an instrument. The values obtained in this study were very similar to the original study, which showed internal consistency of 0.89 for a sample of students and 0.91 for the general population. ${ }^{4}$ In the Spanish sample, Cronbach's alpha was $0.90,{ }^{6}$ while in the samples of Chinese and Pakistani origin, the results were 0.92 and 0.91 , respectively. ${ }^{7}$ The authors of the original instrument also found the alpha at 0.87 in a sample of adolescents. ${ }^{26}$

The Brazilian version of the WEMWBS showed positive correlation with other scales of well-being and mental health validated and used in Brazil, having achieved $\mathrm{r}=0.59$ (moderate correlation) with the WHO-5 scale, and $\mathrm{r}=0.69$ (moderate correlation) with the WBMMS scale. Previous studies involving non-Brazilian samples found a $0.77^{4}$ correlation with WHO-5 and results varying from 0.52 to 0.73 with other scales of psychological well-being manifestation measure. ${ }^{4,6}$

\section{Conclusion}

After item distribution analysis, the study of dimensionality and internal consistency, and confirmatory factor analysis, this study aimed to examine the psychometric properties of the Brazilian version of the WEMWBS, an instrument developed for the purpose of assessing the mental well-being of individuals or populations, due to its easy application and good sensitivity.

As we can see, the results of this study were consistent with those previously described; the time required to answer the questions was short, there was a clear consensus regarding the translation of terms among those involved, and the back-translation was approved by the authors of the original instrument.

The validation process of a questionnaire is complex. In this study, the WEMWBS was translated into Portuguese and adapted to the Brazilian culture but with proper care so that the meaning of the questions was not changed.

Following all the guidelines previously mentioned, from translation to application in a Brazilian sample, we were able to achieve results that prove the validity of the Brazilian version of the WEMWBS. 


\section{ACKNOWLEDGMENTS}

The authors acknowledge the support of Dr. Sarah Stewart-Brown and Dr. Frances Taggart, authors of the original instrument, for supporting the translation and backtranslation stages of the instrument into Portuguese.

\section{Resumo}

Adaptação e validação transcultural da versão brasileira da escala de bem-estar mental de Warwick-Edinburgh.

Objetivo: a escala de bem-estar mental de Warwick-Edinburgh (EBEMWE) foi desenhada para avaliar o nível de bem-estar mental de uma população em geral ou de grupos específicos. A escala é constituída por catorze itens, abrangendo aspectos funcionais psíquicos, assim como bem-estar. O escore final é calculado pela soma das respostas de cada item, cujo valor varia de 1 a 5 , obtendo um resultado total de 14 a 70 pontos.

Métodos: o processo foi desenvolvido de acordo com o protocolo da Organização Mundial da Saúde (OMS), abrangendo tradução, retrotradução, equivalência semântica, avaliação de especialistas das etapas anteriores, pré-teste do instrumento e versão final. Na sequência, a versão final foi aplicada em uma amostra de 122 indivíduos, e os dados obtidos foram submetidos a tratamento estatístico descritivo, análise fatorial, avaliação da consistência interna e correlação com outros instrumentos validados.

Resultados: realizou-se adequação do instrumento para o português utilizado no Brasil, substituindo termos para aproximar a linguagem às expressões do dia a dia. A versão final apresentou resultados similares à versão original, demonstrados pela análise fatorial, pela consistência interna (alfa de Cronbach: 0,89) e pela correlação positiva com instrumentos validados para a língua portuguesa.

Conclusão: a versão brasileira da EBEMWE mostrou-se de fácil aplicação e compreensão, apresentou alta consistência interna e similar validade de construto ao instrumento original.

Palavras-chave: saúde mental, estudos de validação, qualidade de vida, questionários e escalas.

\section{References}

1. WHO. Strengthening Mental Health Promotion 2001 [cited 2013 sept]. Available at: https://apps.who.int/inf-fs/en/fact220.html.

2. Power AK. Transforming the Nations Health: next steps in mental health promotion. Am J Public Health. 2010;100(12):2343-6.

3. Fledderus M, Bohlmeijer ET, Smit F, Westerhof GJ. Mental health promotion as a new goal in public mental health care: a randomized controlled trial of an intervention enhancing psychological flexibility. Am J Public Health. 2010;100(12):2372.
4. Tennant R, Hiller L, Fishwick R, Platt S, Joseph S, Weich S, et al. The WarwickEdinburgh mental well-being scale (WEMWBS): development and UK validation. Health Qual Life Outcomes. 2007;5:63.

5. Stewart-Brown S, Janmohamed K. Warwick-Edinburg mental well-being Scale: User guide. HS Health Scotland; 2008.

6. Lopez MA, Gabilondo A, Codony M, Garcia-Forero C, Vilagut G, Castellvi $\mathrm{P}$, et al. Adaptation into Spanish of the Warwick-Edinburgh mental wellbeing scale (WEMWBS) and preliminary validation in a student sample. Qual Life Res. 2013;22(5):1099-104.

7. Taggart F, Friede T, Weich S, Clarke A, Johnson M, Stewart-Brown S. Cross cultural evaluation of the Warwick-Edinburgh mental well-being scale (WEMWBS) --a mixed methods study. Health Qual Life Outcomes. 2013;11:27.

8. Bartram DJ, Sinclair JM, Baldwin DS. Further validation of the WarwickEdinburgh mental well-being scale (WEMWBS) in the UK veterinary profession: Rasch analysis. Qual Life Res. 2013;22(2):379-91.

9. Bartram DJ, Yadegarfar G, Sinclair JM, Baldwin DS. Validation of the Warwick-Edinburgh mental well-being scale (WEMWBS) as an overall indicator of population mental health and well-being in the UK veterinary profession. Vet J. 2011;187(3):397-8.

10. Lloyd K, Devine P. Psychometric properties of the Warwick-Edinburgh mental well-being scale (WEMWBS) in Northern Ireland. J Ment Health. 2012;21(3):257-63.

11. WHO. Process of translation and adaptation of instruments. [cited 2013 sept]. Available at: http://www.who.int/substance_abuse/research_tools/ translation/en/.

12. Maheswaran H, Weich S, Powell J, Stewart-Brown S. Evaluating the responsiveness of the Warwick Edinburgh Mental Well-Being Scale (WEMWBS): group and individual level analysis. Health Qual Life Outcomes. 2012;10:156.

13. Sapnas KG, Zeller RA. Minimizing sample size when using exploratory factor analysis for measurement. J Nurs Meas. 20021;10(2):135-54.

14. Bech P, Olsen LR, Kjoller M, Rasmussen NK. Measuring well-being rather than the absence of distress symptoms: a comparison of the SF-36 Mental Health subscale and the WHO-Five Well-Being Scale. Int J Methods Psychiatr Res. 2003;12(2):85-91.

15. Massé R, Poulin C, Dassa C, Lambert J, Bélair S, Battaglini A. Élaboration et validation d'un outil de mesure du bien-être psychologique: L'É.M.M.B.E.P. Rev Can Santé Publique. 1998;85(5):352-7.

16. Monteiro S, Tavares, J., Pereira A. Adaptação portuguesa da Escala de Medida de Manifestação de Bem-Estar Psicológico com estudantes universitários EMMBEP. Psicol Saúde \& Doenças. 2012;13(1):66-77.

17. Campesato GA, Pires MLN, Tonon FH, Oliveira DV. Tradução e adaptação cultural para o português brasileiro do instrumento WHO-5, uma escala autoaplicável breve para avaliar bem estar. In: XXII Congresso de Iniciação Científica da UNESP. Marília; 2010.

18. Mingoti SA. Análise de dados através de métodos de estatística multivariada. Belo Horizonte: Editora UFMG; 2005.

19. Effertz T, Mann K. The burden and cost of disorders of the brain in Europe with the inclusion of harmful alcohol use and nicotine addiction. Eur Neuropsychopharmacol. 2013;23(7):742-8.

20. Olesen J, Gustavsson A, Svensson M, Wittchen HU, Jonsson B, Group Cs, et al. The economic cost of brain disorders in Europe. Eur J Neurol. 2012;19(1):155-62.

21. Goncalves RW, Vieira FS, Delgado PG. Mental Health Policy in Brazil: federal expenditure evolution between 2001 and 2009. Rev Saúde Pública. 2012;46(1):51-8.

22. Stewart-Brown S, Tennant A, Tennant R, Platt S, Parkinson J, Weich S. Internal construct validity of the Warwick-Edinburgh mental well-being scale (WEMWBS): a Rasch analysis using data from the Scottish Health Education Population Survey. Health Qual Life Outcomes. 2009;7:15.

23. Urbina S. Fundamentos da testagem psicológica. Porto Alegre: Artmed; 2007.

24. Borsa JC, Damásio BF, Bandeira DR. Adaptação e validação de instrumentos psicológicos entre culturas: algumas considerações. Paidéia. 2012; 22(53):423-32.

25. Williams B, Brown T, Onsman A. Exploratory factor analysis: a five-step guide for novices. J Emerg Prim Health Care. 2010;8(3). [cited 2013 sept]. Available at: http://ro.ecu.edu.au/cgi/viewcontent.cgi?article=1373\&context=jephc.

26. Clarke A, Friede T, Putz R, Ashdown J, Martin S, Blake A, et al. WarwickEdinburgh mental well-being scale (WEMWBS): validated for teenage school students in England and Scotland. A mixed methods assessment. BMC Public Health. 2011;11:487. 